(c) American Dairy Science Association, 2002.

\title{
Antimicrobial Susceptibility of Coagulase-Negative Staphylococci Isolated from Bovine Mastitis in Argentina
}

\author{
E. Gentilini,, ${ }^{*}$ G. Denamiel,, A. Betancor, ${ }^{*}$ \\ M. Rebuelto, ${ }^{*}$ M. Rodriguez Fermepin, $†$ and R. A. De Torres $†$ \\ *Departamento de Fisiopatología y Etiopatogenia \\ Facultad de Ciencias Veterinarias, Universidad de Buenos Aires \\ Chorroarín 280. (1427) Buenos Aires, Argentina \\ †Departamento de Microbiología \\ Facultad de Farmacia y Bioquímica, Universidad de Buenos Aires \\ Junín 965. (1425) Buenos Aires, Argentina
}

\section{ABSTRACT}

A total of 123 isolates of coagulase-negative staphylococci isolated from bovine clinical and subclinical mastitis in Argentina from March 1998 to March 2000 was investigated for in vitro susceptibility to several antimicrobial agents. Minimum inhibitory concentrations that inhibit $90 \%$ of the isolates tested (reported in micrograms per milliliter) were: $4.40,0.38,4.00,0.75,0.75$, 3.60 , and 2.00 for penicillin, oxacillin, cephalothin, gentamicin, erythromycin, clindamycin, and ampicillinsulbactam, respectively. Resistance was detected in 34 (27.6\%), $4(3.2 \%), 7(5.7 \%)$, and $6(4.8 \%)$ isolates for penicillin, oxacillin, erythromycin, and pirlimycin, respectively. No resistance was detected for gentamicin, cephalothin, or ampicillin-sulbactam. Results indicated that coagulase-negative staphylococci isolates in Argentina exhibited the highest degree of resistance to penicillin of all antimicrobial agents tested.

(Key words: Staphylococcus aureus, Streptococcus uberis, bovine mastitis, coagulase-negative staphylococci)

Abbreviation key: $\mathbf{C N S}$ = coagulase-negative staphylococci, $\mathbf{M I C}_{\mathbf{9 0}}=$ MIC required to inhibit $90 \%$ of the isolates tested, $\mathbf{M R}=$ methicillin-resistance, $\mathbf{N C C L S}=$ National Committee of Clinical Laboratory Standards.

\section{INTRODUCTION}

Bovine mastitis is a frequent cause of economic loss in dairy herds. Coagulase-negative staphylococci (CNS) are increasing in importance as causes of bovine IMI throughout the world in recent years. CNS have been isolated from milk samples collected from cows with clinical and subclinical mastitis in several countries

Received April 20, 2001.

Accepted March 4, 2000

Corresponding author: Marcela Rebuelto; e-mail: rebuelto@ fvet.uba.ar.

(McDonald and Anderson, 1981; Miller et al., 1993; Thornsberry et al., 1993, 1997; Aarestrup et al., 1995; Frigerio et al., 1995; Gentilini et al., 1995; Owens et al., 1997; Chaffer et al., 1998; McDougall, 1998; Myllys et al., 1998; Salmon et al., 1998), cause tissue damage (Timms and Schultz, 1987), and decreases in milk production (Trinidad et al., 1990).

Identification of mastitis pathogens is important when selecting appropriate antimicrobial therapy. Beta-lactam antibiotics are frequently used in IMI therapy. Bacterial resistance to beta-lactam mechanisms include production of beta-lactamases and production of a low-affinity penicillin-binding protein, PBP2a (Odd and Maeland, 1997). The latter, designated as methicillin-resistance (MR), precludes therapy with any of the currently available beta-lactam antibiotics, and may predict resistance to several classes of antibiotics besides beta-lactams (NCCLS, 1997, 1999; Odd and Maeland, 1997). Among all staphylococci, MR is encoded by the mecA gene. As MR or multiple resistant phenotypes limit therapeutic options, MIC data and susceptibility tests obtained from mastitis pathogens are essential for successful therapy. Resistance to methicillin (Archer and Climo, 1994), transmissible plasmid trimethoprim (Archer et al., 1986; Galetto et al., 1987), and gentamicin (Archer and Johnston, 1983) have been identified in CNS isolates. Moreover, CNS may function as a reservoir for antibiotic resistant genes to Staphylococcus aureus (Archer and Climo, 1994). Certain CNS isolates have the ability to form biofilms that may interfere with local defenses and impair the activity of bacteriostatic agents such as macrolides when temporary or permanent synthetic devices are implanted (Souli and Giamarellou, 1998). There are no reports on the ability of CNS to form biofilms within the mammary gland.

The purpose of this study was to determine the phenotypic expression of the in vitro susceptibility of CNS isolated from bovine IMI in Argentina to several antimicrobial agents used in the control of this disease. 


\section{MATERIALS AND METHODS}

\section{Bacterial Isolates}

Milk samples $(20 \mathrm{ml})$ were taken aseptically from all quarters of 225 bovine infected udders, and $0.01 \mathrm{ml}$ of each sample was cultured to determine the presence of CNS. A quarter was identified as infected when a single pathogenic bacterium was isolated and SCC were increased above 200,000/ml (Casadevall and Pirofski, 2000). Samples were obtained between March 1998 and March 2000 from the following geographic locations: Buenos Aires, Entre Ríos, Córdoba, Santa Fe, and La Pampa. Bacterial isolation was performed by standard procedures according to National Mastitis Council methods (National Mastitis Council, 1987).

\section{Susceptibility Testing}

For susceptibility testing, isolates were suspended in trypticase soy broth (Laboratorio Britania, Buenos Aires, Argentina), and the suspension was adjusted to a turbidity equivalent to a $0.5 \mathrm{McF}$ arland standard. Drug susceptibility testing was performed by the agar disk diffusion method (Bauer et al., 1966). The following disks were used (Laboratorio Britania, Buenos Aires, Argentina): penicillin, $10 \mathrm{IU}$; oxacillin, $1 \mu \mathrm{g}$; ampicillinsulbactam, $10 \mu \mathrm{g}+10 \mu \mathrm{g}$; gentamicin, $10 \mu \mathrm{g}$; erythromycin, $15 \mu \mathrm{g}$; cephalothin, $30 \mu \mathrm{g}$; and pirlimycin (Becton Dickinson Microbiology Systems, Cockeysville, MD), 2 $\mu \mathrm{g}$. Isolates were categorized as susceptible, intermediate, and resistant based upon interpretive criteria developed by the National Committee of Clinical Laboratory Standards (NCCLS, 1999). For pirlimycin, categories of susceptibility interpretive criteria developed with mastitis pathogens by other investigators were used (Thornsberry et al., 1993). Oxacillin was included for detection of MR because it is more stable than methicillin and provides more reliable results (NCCLS, 1999). Oxacillin resistance is reported as resistance to all $\beta$ lactam antimicrobial agents. When oxacillin resistance was expressed, PCR was done in order to detect presence of mecA gene as previously described (Mo and Wang, 1997).

Staphylococci were tested for $\beta$-lactamase production by the nitrocefin test (Cefinase Discs, Becton Dickinson Microbiology Systems, Sparks, MD) with previous induction with oxacillin. Briefly, Cefinase disks impregnated with nitrocefin, a chromogenic cephalosporin that exhibits a very rapid color change from yellow to red as the $\beta$-lactam ring is hydrolyzed, are dispensed into empty Petri dishes and moistened with one drop of water. With a sterilized loop, several well-isolated similar colonies are smeared onto the disk surface, and observed up to $1 \mathrm{~h}$. If the bacterium produces $\beta$-lacta- mase in significant quantities, the yellow-colored disk turns red. The procedure requires quality control reference organisms to be run with each group of unknowns, Staph. aureus ATCC 29213 is recommended by the manufacturer as the positive control.

For determining MIC, all isolates were tested against the above-mentioned antimicrobial agents (pirlimycin was replaced by clindamycin) by the E-test (AB BIODISK, Solna, Sweden). This test is a quantitative technique consisting of a predetermined exponential gradient of antibiotic immobilized on the surface of a plastic strip. When this strip is applied to an inoculated agar plate, the antibiotic is released, and after incubation, an inhibition ellipse along the strip is observed. The other side of the strip is calibrated with an MIC reading scale $(\mu \mathrm{g} / \mathrm{ml})$. The MIC value is read from the scale where the edge of the ellipse intersects the strip. Quality control reference organisms are required as recommended by NCCLS (NCCLS, 1997). The expected MIC values for these reference strains should fall within the quality control ranges listed for each antibiotic. Staph. aureus ATCC 25923 was used as a control in all of the assays.

\section{RESULTS AND DISCUSSION}

From a total of 900 milk samples collected over $2 \mathrm{yr}$, $123(13.6 \%)$ were positive for CNS. For all of the tests performed, MIC values obtained with control isolates were within the expected reference ranges for all antimicrobial agents tested. The in vitro activities of each of the antimicrobial agents tested against CNS are summarized in Table 1. Bacterial isolates resistant to one antimicrobial agent (mostly penicillin) were 26 (21.13\%); meanwhile, resistance to two or more antimicrobial agents was found in $9(7.31 \%)$ isolates. All isolates were susceptible to gentamicin, cephalothin, and the combination of ampicillin-sulbactam, whereas 34 isolates (27.6\%), 4 isolates (3.2\%), 7 isolates (5.7\%), and 6 isolates $(4.8 \%)$ were resistant to penicillin, oxacillin, erythromycin, and pirlimycin, respectively. Presence of $m e c \mathrm{~A}$ gene was detected in only one isolate expressing oxacillin resistance $(0.8 \%)$. All penicillin-resistant isolates were $\beta$-lactamase producers.

Susceptibility of CNS isolated from bovine IMI to selected antimicrobial agents has been previously reported (McDonald and Anderson, 1981; Thornsberry et al., 1993, 1997; Aarestrup et al., 1995; Frigerio et al., 1995; Watts et al., 1995; Owens et al., 1997; Myllys et al., 1998; Salmon et al., 1998). Penicillin predicts susceptibility to other $\beta$-lactamase-sensitive antimicrobial agents, e.g., ampicillin. CNS $\beta$-lactamase producers will be resistant to penicillins and some cephalosporins. Penicillin-resistance found in our study is in agreement 
Table 1. In vitro susceptibility of 123 isolates of coagulase-negative staphylococci obtained from bovine mastitis to 8 selected antimicrobial agents.

\begin{tabular}{|c|c|c|c|c|c|}
\hline & \multicolumn{3}{|c|}{$\mathrm{MIC}^{1}$} & \multicolumn{2}{|c|}{ Agar disk diffusion test } \\
\hline & $50^{2}$ & $90^{3}$ & Range & Breakpoint & Resistant isolates \\
\hline & $\longrightarrow$ & $-(\mu$ & 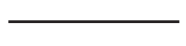 & & No. $(\%)$ \\
\hline Penicillin & 0.064 & 4.40 & $0.006-64.00$ & $\geq 0.25$ & $34 / 123(27.6)$ \\
\hline Oxacillin & 0.250 & 0.38 & $0.016-256.00$ & $\geq 0.5$ & 4/123 (3.2) \\
\hline Cephalothin & 0.750 & 4.00 & $0.032-4.00$ & $\geq 32$ & $0 / 123(0.0)$ \\
\hline Gentamicin & 0.125 & 0.75 & $0.016-3.00$ & $\geq 16$ & $0 / 123(0.0)$ \\
\hline Erythromycin & 0.250 & 0.75 & $0.019-256.00$ & $\geq 8$ & $7 / 123(5.7)$ \\
\hline Clindamycin & 0.250 & 3.60 & $0.094-256.0$ & $\geq 4$ & $\ldots 4$ \\
\hline Pirlimycin & $\ldots 4$ & $\ldots 4$ & & $\geq 4$ & $6 / 123(4.8)$ \\
\hline Ampicillin-sulbactam & 0.125 & 2.00 & $0.016-2.00$ & $\geq 32 / 16$ & $0 / 123(0.0)$ \\
\hline
\end{tabular}

${ }^{1}$ Minimum inhibitory concentration.

${ }^{2}$ Lowest concentration inhibiting $50 \%$ of the isolates tested.

${ }^{3}$ Lowest concentration inhibiting $90 \%$ of the isolates tested.

${ }^{4}$ Test not performed.

with that previously reported for CNS in our country (30\%; Frigerio et al., 1995), but is lower than those reported in studies conducted in Finland (37.2\%; Myllys et al., 1998); Denmark (36.1\%; Aarestrup et al., 1995), and the United States (42.7 and 57\%; McDonald and Anderson, 1981; Owens et al., 1997). A previous study demonstrated that an inducible $\beta$-lactamase was present in 80 to $90 \%$ of human CNS isolates (Archer and Scott, 1991). Other authors reported that $\beta$-lactamase was produced by $34.1 \%$ (Myllys et al., 1998) and $83.6 \%$ (Thornsberry et al., 1997) of the CNS isolates derived from bovine IMI. In our study, MIC for penicillin against $90 \%$ of isolates $\left(\mathbf{M I C}_{\mathbf{9 0}}\right.$ ) was $4 \mu \mathrm{g} / \mathrm{ml}$, well above the recommended breakpoint (NCCLS, 1997); however, $\mathrm{MIC}_{90}$ for penicillin reported in previous studies ranged from $0.25 \mu \mathrm{g} / \mathrm{ml}$ (Salmon et al., 1998) to $32 \mu \mathrm{g} / \mathrm{ml}$ (Thornsberry et al., 1997). These differences in $\mathrm{MIC}_{90}$ values show the variability of the antimicrobial activity of penicillin against CNS and support the importance of determining penicillin susceptibility patterns for CNS. Reported MR-CNS in the United States was higher (7.4\%; Thornsberry et al., 1993) than the MR found in our study. However, in a similar study of antimicrobial susceptibility of Staph. aureus in Argentina, no MR was found (Gentilini et al., 2000).

Gentamicin, cephalothin, and ampicillin-sulbactam were very active against CNS, as all tested isolates were susceptible. Similar results were found in Argentina (Frigerio et al., 1995) and in the United States (McDonald and Anderson, 1981) for gentamicin and cephalothin. MIC were well bellow the recommended breakpoint for these antibiotics (NCCLS, 1997).

Erythromycin resistance reported here $(5.7 \%)$ was lower than 11.5\% (Myllys et al., 1998) and 10\% (Owens et al., 1997) found in previous studies, but higher than that reported for Argentina (1.5\%; Frigerio et al., 1995) and the United States (McDonald and Anderson, 1981). All CNS pirlimycin-resistant isolates were resistant to erythromycin; however, one isolate resistant to erythromycin was pirlimycin susceptible. As erythromycin and pirlimycin have common targets in the bacterial ribosome, organisms that are resistant to one of them may be resistant to the other, and to streptogramines (Macrolide-Lincosamide-Streptogramine resistance, MLSresistance; Barragry, 1994). Pirlimycin resistance found in our study is in agreement with that reported by other authors (Owens et al., 1997).

The role of CNS as a cause of bovine mastitis is not completely clear. CNS infections are associated with damage to milk secretory tissue of the mammary gland by increased connective tissue stroma (Trinidad et al., 1990), moderate increases in milk SCC (Matthews et al., 1991; Chaffer et al., 1998), and significant production decreases (Timms and Schultz, 1987). However, a previous study demonstrated that quarters with preexisting CNS infections were less likely to become infected by new major mastitis pathogens than uninfected quarters, suggesting some potential benefit from their presence (Mathews et al., 1991). The role of CNS as a possible reservoir for resistance among staphylococci has been determined (Archer and Climo, 1994). When isolating resistant CNS from bovine IMI, antimicrobial therapy would be indicated; however, when the presence of the MR-CNS isolate or multi-resistant CNS is detected, as in this study, the animals should be culled. Even though the resistance detected in this study was low, if the occurrence of resistant CNS increases, the appropriate therapy may become a serious clinical problem. CNS resistance in dairy herds in Argentina must be monitored continuously in order to develop susceptibility patterns and to establish trends in CNS resistance and appropriate drycow therapy. 
Bacterial identification and susceptibility tests are important for selecting the appropriate antimicrobial agent when treating bovine mastitis. However, several factors may account for the lack of a relationship between antimicrobial susceptibility tests results and treatment success. Recommended NCCLS antimicrobial breakpoints used to categorize organisms as resistant or susceptible are determined for human pathogens and human pharmacological data, and the importance of the role that milk may play in the activity of the antibiotic has not been considered. The addition of milk to the susceptibility test medium reduced inhibition zone diameters of novobiocin, streptomicin, gentamicin, tetracycline, and vancomycin compared with inhibition zone diameters obtained by the standard method (Owens and Watts, 1987). Thus, the NCCLS guidelines may not be appropriate to determine the antimicrobial susceptibility of bovine mastitis pathogens, and veterinary guidelines should be determined. Poor penetration of the antibiotic at the site of infection may impair the antimicrobial efficacy. Cure rates of pathogens that invade tissues, such as Staph. aureus chronic infections, are lower than cure rates for pathogens confined primarily to milk, such as Streptococcus spp. and recent infections of Staph. aureus (Owens et al., 1997). The dose, duration, and route of administration of the therapeutic agent may affect treatment outcome, as antibiotic concentration and duration of exposure is related to antimicrobial activity (Barragry, 1994).

Food animals may serve as a reservoir of resistant bacteria that may disseminate to human beings. Worldwide concern over the emergence of resistant bacteria in domestic animals and its influence on human medicine is mostly linked to the use of antibiotics as growth promoters, even though some data may be controversial (Descheemaeker et al., 1999; Stobberingh et al., 1999; Aarestrup et al., 2001). However, the use of antimicrobial therapy must be prudent, as the exposure to any antibiotic produces a selective pressure in favor of resistant bacteria.

\section{CONCLUSIONS}

In recent years, CNS are emerging as important minor mastitis pathogens and can be the cause of substantial economic losses. The high resistance to penicillin plus the presence of MR isolates found in this study emphasize the importance of identification of CNS when an IMI is present. Antimicrobial susceptibility patterns should be identified for CNS, as current susceptibility data are necessary to select appropriate antibiotics for a successful treatment. Further studies are necessary for assessing the importance of IMI caused by CNS in Argentina.

\section{ACKNOWLEDGMENTS}

This study was supported by the Secretaría de Ciencia y Técnica, Universidad de Buenos Aires, project TV15. The authors thank Romage S.A. for providing the pirlimycin disks and the milk samples used in this study.

\section{REFERENCES}

Aarestrup, F. M., A. M. Seyfarth, H. D. Emborg, K. Pedersen, R. S. Hendriksen, and F. Bager. 2001. Effect of abolishment of the use of antimicrobial agents for growth promotion on occurrence of antimicrobial resistance in fecal enterococci from food animals in Denmark. Antimicrob. Agents Chemother. 45:2054-2059.

Aarestrup, F. M., H. C. Wegener, V. T. Rosdahl, and N. E. Jensen. 1995. Staphylococcal and other bacterial species associated with intramammary infections in Danish dairy herds. Acta vet. Scand. $36: 475-487$

Archer G. L., and J. Scott. 1991. Conjugative transfer genes in staphylococcal isolates from the United States. Antimicrob. Agents Chemother. 35:2500-2504.

Archer, G. L., and M. W. Climo. 1994. Antimicrobial susceptibility of coagulase-negative staphylococci. Antimicrob. Agents Chemother. 38:2231-2237.

Archer, G. L., and L. J. Johnston. 1983. Self-transmissible plasmids in staphylococci that encode resistance to aminoglycosides. Antimicrob. Agents Chemother. 24:70-77.

Archer, G. L., J. P. Coughter, and L. J. Johnston. 1986. Plasmidencoded trimethoprim resistance in staphylococci. Antimicrob. Agents Chemother. 29:733-740.

Barragry, T. B. 1994. Veterinary Drug Therapy. 1st ed. Lea \& Febiger, Pennsylvania.

Bauer, A. W., W. M. M. Kirby, J. C. Sherris, and M. Turck. 1966 Antibiotic susceptibility testing by a standardized single disk method. Am. J. Clin. Pathol. 45:493-496.

Casadevall, A., and L. A. Pirofski. 2000. Host-pathogens interactions: Basic concepts of microbial commensalism, colonization, infection and disease. Infect. Immun. 68:6511-6518.

Chaffer, M., G. Leitner, M. Winkler, and A. Saran. 1998. Coagulasenegative Stahpylococcus intermedius isolated from milk from dairy cows in Israel. Vet. Rec. 143:592-593.

Descheemaeker, P. R., S. Chapelle, L. A. Devriese, P. Butaye, P. van Damme, and H. Goossens. 1999. Comparison of glycopeptideresistant Enterococcus faecium isolates and glycopeptide resistance genes of human and animal origins. Antimicrob. Agents Chemother. 43:2032-2037.

Frigerio, C., S. Bettera, I. Scalise, J. Giraudo, and A. Calzolari. 1995. Resistencia a antibióticos de cepas de estafilococos aisladas en tres tambos de Córdoba, Argentina. Rev. Med. Vet. 76:288-292.

Galetto, D. W., L. J. Johnston, and G. L. Archer. 1987. Molecular epidemiology of trimethoprim resistance among coagulase-negative staphylococci. Antimicrob. Agents Chemother. 31:1683-1688.

Gentilini, E., G. Denamiel, P. Llorente, S. Godaly, M. Rebuelto, and O. Degregorio. 2000. Antimicrobial susceptibility of Staphylococcus aureus isolated from bovine mastitis in Argentina. J. Dairy Sci. 83:1224-1227.

Gentilini, E., G. Denamiel, and S. Godaly. 1995. Mastitis bovina: Tipificación del género Staphylococcus. Vet. Arg. XII:384-386.

Matthews, K. R., R. J. Harmon, and B. E. Langlois. 1991. Effect of naturally occurring coagulase-negative Staphylococci infections on new infections by mastitis pathogens in the bovine. J. Dairy Sci. 74:1855-1859.

McDonald, J. S., and A. J. Anderson. 1981. Antibiotic sensitivity of Staphylococcus aureus and coagulase negative staphylococci 
isolated from infected bovine mammary glands. Cornell Vet. 71:391-396.

McDougall, S. 1998. Efficacy of two antibiotic treatments in curing clinical and subclinical mastitis in lactating dairy cows. N.Z. Vet. J. 46:226-232.

Miller, G., P. C. Bartlett, S. E. Lance, J. Anderson, and L. E. Heider. 1993. Costs of clinical mastitis and mastitis prevention in dairy herds. JAVMA 202:1230-1236.

Mo, L., and Q. Wang. 1997. Rapid detection of methicillin-resistant staphylococci using polymerase chain reaction. Int. J. Infect. Dis. $2: 15-20$.

Myllys, V., K. Asplund, E. Brofeldt, V. Hirvelä-Koski, T. HonkanenBuzalski, J. Junttila, L. Kulkas, O. Myllykangas, M. Niskanen, H. Saloniemi, M. Sandholm, and T. Sarampää. 1998. Bovine mastitis in Finland in 1988 and 1995-Changes in prevalence and antimicrobial resistance. Acta Vet. Scand. 39:119-126.

National Committee for Clinical Laboratory Standards. 1997. Methods for dilution antimicrobial susceptibility tests for bacteria that grow aerobically. 3rd ed. Approved Standard. Document M7-A4. Natl. Committee Clin. Lab. Stand., Wayne, PA.

National Committee for Clinical Laboratory Standards. 1999. Performance standards for antimicrobial susceptibility testing; Ninth Informational Supplement. Document M100-S9. Natl. Committee Clin. Lab. Stand., Wayne, PA.

National Mastitis Council. 1987. Laboratory and Field Handbook on Bovine Mastitis. Natl. Mastitis Counc., Inc., Arlington, VA.

Odd, G. B., and J. A. Maeland. 1997. Mechanisms of methicillin resistance in staphylococci. AMPIS. 105:264-276.

Owens, W. E., C. H. Ray, J. L. Watts, and R. J. Yancey. 1997. Comparison of success of antibiotic therapy during lactation and results of antimicrobial susceptibility test for bovine mastitis. J. Dairy Sci. 80:313-317.

Owens, W. E., and J. L. Watts. 1987. Effects of milk on activity of antimicrobics against Staphylococcus aureus isolated from bovine udders. J. Dairy Sci. 70:1946-1951.
Salmon, S. A., J. L. Watts, F. M. Aarestrup, J. W. Pankey, and R. J. Yancey, Jr. 1998. Minimum inhibitory concentrations for selected antimicrobial agents against organisms isolated from the mammary glands of dairy heifers in New Zealand and Denmark. J. Dairy Sci. 81:570-578.

Souli, M., and H. Giamarellou. 1998. Effects of slime produced by clinical isolates of coagulase-negative staphylococci on activities of various antimicrobial agents. Antimicrob. Agents Chemother. 42:939-941.

Stobberingh, E., A. van den Boggard, N. London, C. Driessen, J. Top, and R. Willems. 1999. Enterococci with glycopeptide resistance in turkeys, turkey farmers, turkey slaughterers, and (sub)urban residents in the south of The Netherlands: evidence for transmission of vancomycin resistance from animals to humans? Antimicrob. Agents Chemother. 43:2215-2221.

Thornsberry, C., J. K. Marler, J. L. Watts, and R. J. Yancey, Jr. 1993. Activity of pirlimycin against pathogens from cows with mastitis and recommendations for disk diffusion tests. Antimicrob. Agents Chemother. 37:1122-1126.

Thornsberry, C., P. J. Burton, Y. C. Yee, J. L. Watts, and R. J. Yancey, Jr. 1997. The activity of a combination of penicillin and novobiocin against bovine mastitis pathogens: development of a disk diffusion test. J. Dairy Sci. 80:413-421.

Timms, L. L., and L. H. Schultz. 1987. Dynamics and significance of coagulase-negative staphylococcal intramammary infections. J. Dairy Sci. 70:2648-2657.

Trinidad, P., S. C. Nickerson, and R. W. Adkinson. 1990. Histopathology of staphylococcal mastitis in unbred dairy heifers. J. Dairy Sci. 73:639-647.

Watts, J. L., S. A. Salmon, R. J. Yancey, Jr., S. C. Nickerson, L. J. Weaver, C. Holmberg, J. W. Pankey, and L. K. Fox. 1995. Antimicrobial susceptibility of microorganisms isolated from the mammary glands of dairy heifers. J. Dairy Sci. 78:1637-1648. 